\title{
Nature of Textile Teachers Instructional Approaches and Students Skills Acquisition in Ghana Senior High School Classrooms
}

\author{
Johnson Kofi Kassah ${ }^{1,}$, , Jacqueline Kisato ${ }^{2}$, Agbeyewornu Kofi Kemevor ${ }^{3}$ \\ ${ }^{1}$ Department of Vocational Education, St. Francis College of Education, Hohoe, Ghana \\ ${ }^{2}$ Department of Fashion, Design \& Marketing, Kenyatta University, Nairobi, Kenya \\ ${ }^{3}$ Department of Graphic Design, University of Education-Winneba, Winneba, Ghana \\ Email address: \\ johnson.kassah@yahoo.com (J. K. Kassah) \\ *Corresponding author
}

\section{To cite this article:}

Johnson Kofi Kassah, Jacqueline Kisato, Agbeyewornu Kofi Kemevor. Nature of Textile Teachers Instructional Approaches and Students Skills Acquisition in Ghana Senior High School Classrooms. International Journal of Secondary Education.

Vol. 7, No. 4, 2019, pp. 101-106. doi: 10.11648/j.ijsedu.20190704.12

Received: August 20,2019; Accepted: September 16, 2019; Published: October 14, 2019

\begin{abstract}
The purpose of this study was to investigate Ghana senior high school textile teachers' instructional approaches and students' practical skills acquisition. The study employed a cross-sectional survey design. The study targeted senior high school textile teachers, graduates and heads of visual arts department in Ghana senior high schools. The sample size for the study was 243 (225 teachers, 12 textile graduates \& 6 HoDs). The study employed a questionnaire, document analysis, an interview guide and non-participant observation as research instruments for data collection. The findings of the study indicated that the textile training curriculum has enough practical components to equip learners with employable skills. The study also found out that most textile teachers used teacher-centred instructional methods of teaching such as lecture and whole class discussion methods than hands-on instructional methods such as demonstration, project method, field trip, learning by doing, and work-based learning. The study recommended that textile teachers should be encouraged to always use hands-on instructional approaches such as demonstration, project method and fieldtrip. Work-based (industrial attachment) which is not part of Ghana senior high schools textile system should be introduced into the curriculum.
\end{abstract}

Keywords: Instructional Approaches, Skills Acquisition, Textiles

\section{Introduction}

Ghana senior high school textile curriculum is designed to equip learners with the knowledge and skills to improve production in the textile industry and to empower the textile students with employable skills in order to employ themselves and others in order to boost economy [1]. The knowledge, skill and technology obtained through textile training enables learners with practical and management skills needed for employment generation that can curtails poverty [2]. Students' employable skills competencies can only be attained when trainers adopt effective and efficient teaching strategies [3]. In recent times, attention to quality skill training has increasingly turned to pedagogical strategies in the classroom [4]. Educational stakeholders in textile training across the globe are passionately evaluating teaching styles that can help improve textile students' employable skills achievements. Undeniably, effective classroom instructional strategies have been recognised as vital tools for encouraging learners' achievement in vocational skills [5]. In North America, learner-centred teaching styles have gradually gained attention in classrooms and have been rated as the topmost instructional approaches that aid learners to a better understanding 21 st century classroom [6]. International reports on practical skills acquisition in the formal education classroom suggest that the world's top performing school systems have recognised that the most imperative means to advance employable skill acquisition outcomes in the classroom is by using 
instructional methods that facilitate easy skill competencies. The major purpose of introducing textile into senior high school curriculum is to train textile artist, technicians and technologists for both large and small scale textile industries in Ghana and also to produce graduates with employable skills in textile that can create jobs for themselves and other especially the vulnerable in the country.

\subsection{Statement of the Problem}

The main emphasis on Ghana senior high school textile training is that it is the key producer of textile artist, engineers and technologists that are employed in the textile industries and the informal sector of the economy. But over the years these have not been achieved. This may be due to the nature of the instructional methods used by textile teachers. This study was to access the nature of instructional approaches used by Ghana senior school textile teachers in training their students.

\subsection{Objectives of the Study}

i. To identify employable skills in textile production Ghana senior high school textile students are exposed to during the 3 years of textile training.

ii. To find out the nature of pedagogical strategies used by Ghana senior high school textile teachers in training their students.

\subsection{Research Question}

i. What are the employable skills Ghana senior high school textile students are exposed to during the 3 years of textile training?

ii. What are the nature of pedagogical strategies used by Ghana senior high school textile teachers in training their students?

\section{Research Design}

The purpose of this article was to investigate nature of textile teachers' instructional approaches and students' skills acquisition in Ghana senior high school classrooms. To address the objectives of the study, the study employed crosssectional survey design to collect both quantitative and qualitative data from Ghana senior high school textile teachers, textile graduates working in the indigenous textile industry heads of visual arts department. The cross-sectional design was preferred because it allows a large amount of data to be collected within a short time [7]. Zheng [8] states that a cross-sectional survey is the type of research design in which the researcher collects data on only a small portion of the population to obtain information about the sampled elements of the population as a whole.

\subsection{Target Population}

According to Alvi [9], target population is the group of elements to which the researcher intends to obtain his or her data from. Target population refers to all the elements who meet the particular condition outlined for a research study [9]. Target population refers to a group of persons with distinctive features which a researcher wants to study and collect data [10]. This study targeted 346 senior high school textile teachers, 6 visual arts department HoDs and 12 textile graduates who are owners/managers of the indigenous textile industry in the three regions namely Volta, Ashanti and Northern regions. Table 1 indicates the breakdown of the groups in the target population.

Table 1. Target Population.

\begin{tabular}{ll}
\hline Group & Population \\
\hline Senior High School Textile Teachers & 346 \\
Senior High Textile Graduate & 12 \\
HoDs & 6 \\
Total & 364 \\
\hline
\end{tabular}

\subsection{Sampling Techniques}

Purposive sampling, simple random sampling, and snowball were used in this study to enable the researcher to get relevant information needed for study. The purposive sampling was adopted to select only senior high schools offering the textile programme, teachers with textile background teaching textiles and visual arts heads of department. Purposive sampling in qualitative research is the careful selection of participants with specific features in accordance to the needs of the emerging analysis theory [11]. Simple random sampling was used to select the senior high school textile teachers in the three regions targeted. Simple random sampling was used because the researcher could not collect data from all 346 senior high school textile teachers in the three regions. Simple random sampling is a technique in which every subject of the target population has an equal opportunity to be selected [9].

Snowball sampling technique was employed to trace 12 senior high school graduates working in the indigenous textile industry in Volta, Ashanti and Northern regions of Ghana to provide relevant information for this study. This sampling was employed because getting information about the location of the textile graduates was difficult for the researcher. Snowball sampling is normally employed when the target population cannot be found in a particular place [12]. In this sampling technique, the researcher asks each subject to give him or her access to his colleagues from the same population [13].

\subsection{Sample Size}

Sampling was carried out in this study because the target population was a very scattered population and so it was impossible to collect data from all the 346 textile teachers in the target population. A sample is a collection of individuals from a population one is interested to study [14]. Hill [15] states that with the population of 30 to 500 , the use of about $10 \%$ size of the population is recommended. Little populations, a sample size of about $20 \%$ of the inhabitants is an excellent representation whilst for huge 
populations a sample size of $10 \%$ representative is adequate [16].

The researcher therefore, sampled $50 \%$ of the textile teachers' population out of 346 to obtain 173. However, the researcher hypothesised that some teachers may not return their questionnaires and so the sample size for the teachers was $30 \%$ upward adjusted to cater for noncompliance [17]. The teachers sample size for the study was 225. Table 2 below indicated the breakdown of the total sample size.

Table 2. Sampling Grid of Participants for the Study.

\begin{tabular}{lll}
\hline Participants & Population & Sampled \\
\hline SHS Textile Teachers & 346 & 225 \\
SHS Textile Graduates & 12 & 12 \\
HODs & 6 & 6 \\
Total & 364 & 243 \\
\hline
\end{tabular}

\subsection{Instrumentation}

According to Anum [18], research instruments are the instruments or tools that aid a researcher to collect his or her data and they include a questionnaire, an interview guide, and observation. Research instruments are what a researcher use for collecting information (data) to answer his/her research questions [19]. This study employed 4 data collection instruments namely; questionnaire, document analysis, interview guide and non-participant observation. The questionnaire was used to collect data from the Ghana senior high school textile teachers about the nature of instructional approaches they used to equip students with practical skills. The document analysis was used to assess the practical component of the Ghana senior high school textile training curriculum. The interview guide was used to amass data from the senior high school textile graduates who have created employment for themselves and others. The nonparticipant observation was used to perceive the nature of instructional strategies used by Ghana senior high school textile teachers in order to authentic the data obtained through the use of the questionnaire.

\section{Findings}

Nature of Pedagogical Strategies Used by Textile Teachers in Training their Students.

The second objective of this study was to investigate the nature of pedagogical strategies Ghana Senior High School textile teachers use in training their students The teachers were asked to rate how often they use various pedagogical strategies during teaching. The results in table 3 indicated textile teachers responses on the nature of instructional methods used in training their students.

Table 3. Nature of instructional methods Used by Textile Teachers.

\begin{tabular}{|c|c|c|c|c|}
\hline Pedagogical Strategy & Never & Rarely & Often & Always \\
\hline Lecture & $0(0.0 \%)$ & $0(0.0 \%)$ & $58(28.2 \%)$ & $148(71.8 \%)$ \\
\hline Discussion & $0(0.0 \%)$ & $33(16 \%)$ & $173(84 \%)$ & $0(0.00 \%)$ \\
\hline Demonstration & $45(21.8 \%)$ & $136(66 \%)$ & $25(12.2 \%)$ & $0(0.0 \%)$ \\
\hline Project & $197(95.6 \%)$ & $9(4.4 \%)$ & $0(0.0 \%)$ & $0(0.0 \%)$ \\
\hline Field Trip & $186(90.3 \%)$ & $20(7.7 \%)$ & $0(0.0 \%)$ & $0(0.0 \%)$ \\
\hline Work- Based & $206(100 \%)$ & $0(0.0 \%)$ & $0(0.0 \%)$ & $0(0.0 \%)$ \\
\hline
\end{tabular}

Results in table 3 indicated that majority of the textile teachers $(n=148,71.8 \%)$ used lecture method of teaching always while $(\mathrm{n}=58,28.2 \%)$ often use the lecture method in their teaching. The results in table 3 also show that apart from lecture method, majority of the textile teachers $(n=173$, $84 \%$ ) often use discussion method to teach their learners whilst $(n=33,16 \%)$ rarely used the discussion method to teach. Concerning demonstration method of teaching, majority of the textile teachers $(n=136,66 \%$ rarely used the demonstration method in teaching, $(n=45,21.8 \%)$ never used it while $(n=12,2 \%)$ often used the demonstration method to train their learners.

It was also revealed in table. 3 that $(n=197,95.6 \%)$ teachers never used project method of teaching in training their textile students whilst $(n=9,4.4 \%)$ rarely used project method in teaching. In field trip method of teaching, $(n=186,90.3 \%)$ teachers never used the method and $(n=20.7 .3 \%)$ rarely used the method in teaching. Regarding the work-based method of teaching, all the teachers $(n=206,100 \%)$ said they never used this method before since it is not part of the requirement for the award of grade in textile at Ghana senior high schools. The results above indicate that majority of textile teachers never or rarely used appropriate vocational pedagogical strategies in teaching the skills needed to modernise the indigenous textile industry in Ghana. This has implications that the skills of textile graduates are often compromised.

\section{Discussions}

Objective 1: To identify employable skills in textile production Ghana senior high school textile students are exposed to during the 3 years of textile training.

The objective 1 of this study was to identify employable skills in textile production Ghana senior high school textile students are exposed to during the 3 years of textile training. Table 4 shows the kind of employable skills textile students are exposed to during their 3 years of training. 
Table 4. Employable skills Ghana Senior High School textile students are exposed to.

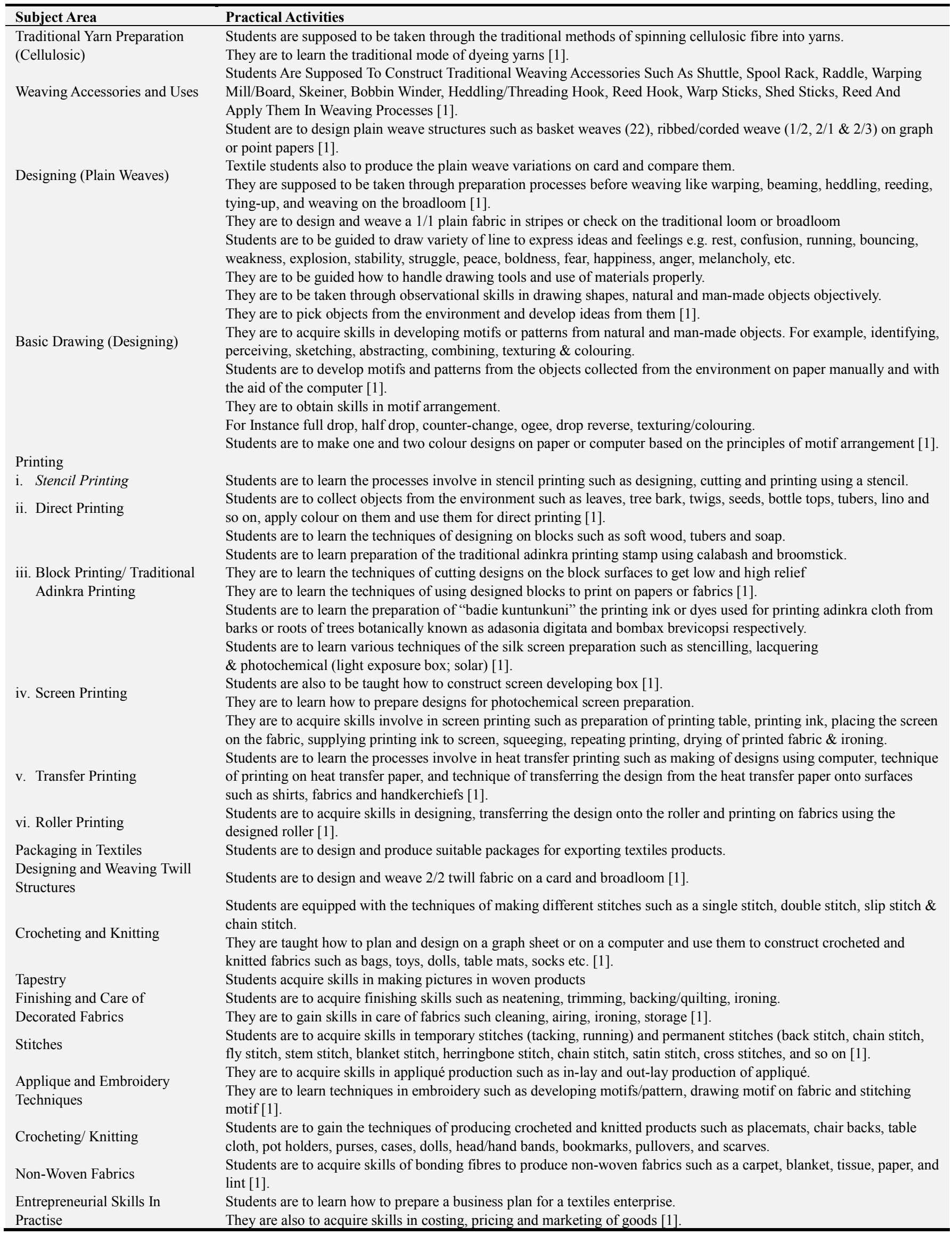


Objective 2: To establish the nature of pedagogical strategies used by Ghana senior high school textile teachers in training their students.

The nature of pedagogical strategies is how teaching and learning processes are conducted in and outside the classroom. The results obtained from the questionnaire, interview schedule and observation showed that majority of the textile teachers used lecture and discussion methods always or often during the delivery of most of the textile topics than any other instructional strategies while a few teachers used the method rarely.

These findings in support of Kimotho [20] who states that the use of traditional lecture teaching approach usually produces poor results because of poor retention ability due to the fact that the average amount of information retained through the use of lecture method of teaching is only $5 \%$. The present findings are also in corroboration with Yusofa, Roddin \& Awang [21] who are of the view that lecture method of teaching has found to boundary learners active involvement in classroom learning process which indirectly becomes a limitation for learners to facilitate the integration of knowledge and skills prior to transferring it into a real employment situation.

Higher number of the textile teachers indicated that they often used discussion method of teaching while a fewer number of them said they rarely used it. Data obtained from interview and observation in the classroom validated the findings obtained from the questionnaire. The use of discussion method of teaching textiles concur to Rahman et al. [22] who state that using discussion method of teaching can be an efficient means of aiding leaners to apply abstract ideas and critical thinking about what is learnt in the classroom.

Majority of the textile teachers indicated they rarely used demonstration method in teaching whilst fewer number of them said they often or never used this method. These findings are not in conformity with Veselinovska [23] who states that learners remember $10 \%$ of what they read, $20 \%$ of what they heard, $30 \%$ of what they saw and $90 \%$ of what they observed and did. When taught using demonstration. The findings are also not agreement with the findings of Williams and McClure [24] who opined that knowledge and skill retention is high and always consistent over time for the learners who received their learning process through demonstration than lecture and discussion method of teaching. The present findings are also not in agreement with Auwal [25] who is of the view that demonstration method of teaching and learning brings about better retention of learned materials than lecture and discussion methods of teaching.

The results obtained from project method of teaching showed that majority of the textile teachers never used project method of teaching while less number of them rarely used this method of teaching. The findings of the study also indicated that majority of the textile teachers never used field trip method of teaching while a very small number used it.

About work-based method of teaching, all the teachers said they never used it since it is not part of the textile curriculum. These current findings are not in agreement with Audu (4) who stated that the most appropriate and effective pedagogical strategies to use in order to aid learners to acquire skills needed to transform industries are work-based learning, demonstration, fieldtrip, and project work and methods. These findings confirm Sithole [26] findings which concluded that because of the fear of sacrificing the syllabus, teachers infrequently used action-oriented teaching approaches which make them to cover content on time at the expense of in-depth coverage.

The effect of these findings is that since the relevant vocational pedagogical strategies are rarely or never used in training textiles students in Ghana senior high schools, the skills textile students need to modernise the indigenous textile industry might have been compromised.

\section{Conclusions}

The purpose of this study was to investigate Ghana senior high school textile teachers' instructional approaches and students' practical skills acquisition. Based on the findings of the study, the study concluded that the textile training curriculum has enough practical component to equip learners with employable skills. The study also concluded that most textile teachers used lecture and discussion instructional strategies always or often than skills acquisition pedagogical strategies such as demonstration, project method, field trip and work-based learning.

\section{Recommendations}

Based on the findings of the study, the study recommended the following:

i. Textile teachers should be encouraged to always use hands-on instructional approaches such as demonstration, project method and field trip.

ii. Work-based (industrial attachment) which is not part of Ghana senior high schools textile system should be introduced into the curriculum.

\section{References}

[1] Curriculum Research and Development Division, (2010). Teaching syllabus for textiles (SHS 1-3). Accra, Ghana: Ministry of Education.

[2] Anindo, J. (2016). Institutional factors influencing acquisition of employable skills by students in public technical and vocational education and training institutions in Nairobi County, Kenya. School of Education, University of Nairobi.

[3] Audu, R. (2014). Assessment of the teaching methods that influence the acquisition of practical skills. Asian social science, 10 (21), 35-41. 
[4] Mir, G. A. T. (2013). What is my pedagogy? Shifting understandings and practices of teachers in Government schools in Kashmir, India (master's thesis). Graduate Department of Curriculum, Teaching and Learning Ontario Institute for Studies in Education, University of Toronto.

[5] Nasimiyu, G. (2017). Preparation of teacher-trainees in pedagogy in Kenyan universities. Journal of Education and Practice, 8 (13), 28-34.

[6] Zwaagstra, M. C., Clifton, R. A., \& Long, J. C. (2010). What's wrong with our schools: And how we can fix them. Lanham, MD: Rowman \& Littlefield Education.

[7] Rose, S., Spinks, N. \& Canhoto, A. I. (2015). Management research: Applying the principles. New York: Routledge.

[8] Zheng, M. (2015). Conceptualization of cross-sectional mixed methods studies in health science: A methodological review. International Journal of Quantitative and Qualitative Research Methods, 3 (2), 66-87.

[9] Alvi, M. (2016). A manual for selecting sampling techniques in research. University of Karachi, Iqra University.

[10] Arthur-Nyarko, E. (2017). Learner characteristics and responsiveness to E-learning delivery in selected distance education institutions in Ghana ( $\mathrm{PhD}$ Thesis). Department of Educational Communication Technology, Kenyatta University.

[11] Burke, J. R. \& Christensen, L. (2014). Educational research: Quantitative, qualitative, and mixed approaches (5th edition). United States of America: SAGE.

[12] Limboro, C. M. (2012). Skills training in engineering courses in institutes of technology and the labour market requirements in Kenya ( $\mathrm{PhD}$ thesis). School of Education, Kenyatta University.

[13] Elfil, M. \& Negida, A. (2017). Sampling methods in clinical research: An educational Review. Department of Medical Sciences, University of Medical Sciences.

[14] Malone, H. E. \& Coyne, L. (2016). Fundamentals of estimating sample size. Retrieved from https://www.researchgate.net/publication/303312866.

[15] Hill, R. (2012). What sample size is "enough" in internet survey research? Interpersonal computing and technology. An Electronic Journal for the 21st Century, 6 (4), 1-10.

[16] Bosibori, O. E. (2012). Role of product range, network associations and marketing strategies in business performance of textile handicraft traders in Nairobi, Kenya
(PhD thesis). School of Applied Human Sciences, Kenyatta University.

[17] McConnell, B. \& Vera-Hernandez, M. (2015). Going beyond simple sample size calculation: A Practioner's guide. Institute for Fiscal Studies Working Paper W15/17.

[18] Anum, G. (2017). Research instruments for data collection. Department of Fine Art and Media Art Technology, Kwame Nkrumah University of Science and Technology.

[19] Kok- Eng, T. (2013). Adapting or adopting an instrument for your study. School of Educational Studies, Universiti Sains Malaysia.

[20] Kimotho, R. M. (2016). Pedagogical challenges facing the teaching of business studies and impact on students achievement in secondary schools in Nyandarua CountyKenya (Master's thesis). Department of Educational Communication and Technology, Kenyatta University.

[21] Yusof, Y., Roddin, R. \& Awang, H. (2015). What students need, and what teacher did: The impact of teacher's teaching approaches to the development of students' generic competences. Procedia-Social and Behavioral Sciences 204, 36-44.

[22] Rahman, F., Khalil, J. K., Jumani, N. B., Ajmal, M., Malik, S. \& Sharif, M. (2011). Impact of discussion method on students performance. International Journal of Business and Social Science, 2 (7), 84-94.

[23] Veselinovska, S. S. (2011). The effect of teaching methods on cognitive achievement, retention, and attitude among in biology studying. Cypriot Journal of Educational Sciences, 4 (1) $175-185$.

[24] Williams, J. \& McClure, M. (2010). The effects of teaching methods in leadership knowledge retention: An experimental design of lecture, experiential, and public pedagogy. $J$. Leadersh. Education, 9 (2), 86-100.

[25] Auwal, A. (2013). Effects of teaching method on retention of agricultural science knowledge in senior secondary schools of Bauchi local government area, Nigeria. International Journal of Science and Technology Educational Research, 4 (4), 6366.

[26] Sithole, B. M. (2012). Pedagogical practices of business studies teachers in Botswana junior secondary schools: Are teachers and curriculum planners singing from the same hymnbook? International Journal of Scientific Research in Education, 3, 21-28. 